\title{
Optimization and Experimental Investigation of the Ability of New Material from Aluminum Casting on Pumice Particles to Reduce Shock Wave
}

\author{
Masoud Rahmani ${ }^{\star *}$, Amin Moslemi Petrudi ${ }^{1}$ \\ ${ }^{1}$ Department of Mechanical Engineering, Tehran University, Tehran, P. O. B. 14155-6619, Iran \\ * Corresponding author, e-mail: msrahmani@ihu.ac.ir
}

Received: 19 March 2020, Accepted: 04 May 2020, Published online: 30 June 2020

\begin{abstract}
Some materials, due to their inherent properties, can be used as shock and wave absorbers. These materials include foam and porous materials, in this study, specimens were made by casting aluminum on porous mineral pumice. Which can replace aluminum foam in some applications with lesser cost, at first, the material is compared with aluminum foam using compression test and quasi-static loading diagram. Which compares the diagrams of these two materials showing the similarity of their behavior in quasi-static loading. Initially, the elastic bending of the walls causes an elastic region in the stress-strain curve of the material. Then, the plastic collapsing of the cells forms a large and relatively smooth region along the elastic and after the plastic collapse of the cells, the area known as foam densification begins where the density of the foam closer to the density of its constituent material causes a sudden increase in the stress level in the specimen. These steps have also been seen in the quasi-static loading of aluminum foam. Then, by using numerical simulations with ANSYS AUTODYN and the shock tube test the ability of these specimens were investigated to reduce the shock wave. The behavior of the material in this case is also very similar to the results of previous studies on aluminum foam.
\end{abstract}

Keywords

aluminum foam, porous materials, casting aluminum, experimental test

\section{Introduction}

Mitigation of impact energy, shock waves and noise is considered in many industries, including automotive, construction and military industries. Porous materials have always been considered due to their shock-reducing effects in various protective applications. Nature evolved in many cases with low-density cellular material. The structural composition of very light cellular materials as core, and strong and dense outer surfaces, they made columns of tall trees to withstand the bending forces of strong winds, and they made bones like beams to support weight. One of the porous materials used in industry is aluminum foam. Aluminum foam is one of the advanced materials, and the cost of making aluminum foam is relatively high due to the equipment required and the manufacturing process. The purpose of this study is to fabricate aluminum foam-like structures that can be replaced in some applications at a much lower price. This structure is made by casting aluminum on mineral pumice grains. Fig. 1 is an example of the structure of a beak and wing bone of a bird and human skull showing how nature has used this clever design to create structures that can withstand high bending and impact loads at least weight.

Numerical simulation are also widely applied to study the mechanical behavior and mechanisms of cellular metals.

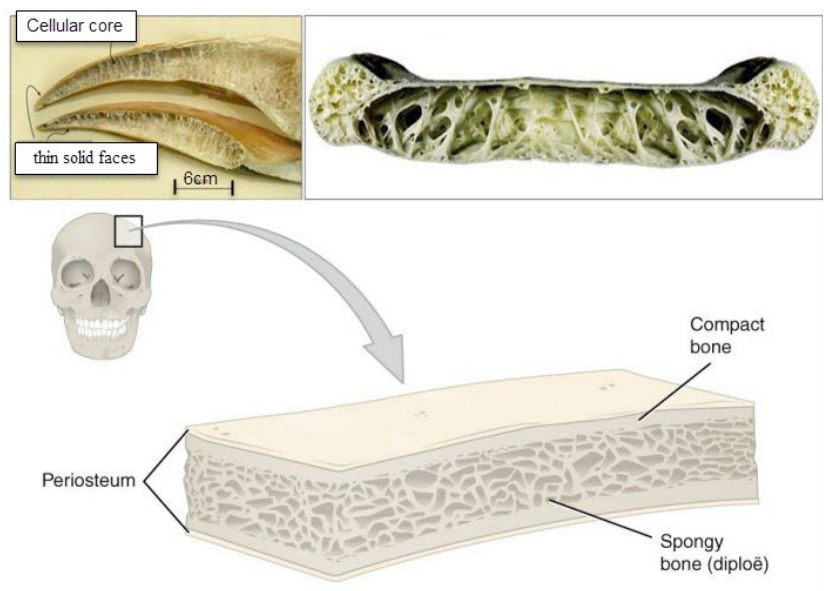

Fig. 1 An example of the beak and bone structure of a bird and human skull. 
Many works have been done to reveal the mechanical properties of metallic foams under static loading; Kenny [1] researched the dependence of the specific energy absorbed by Alcan ${ }^{\circledR}$ foams on strain rates in the range of $10^{-1}-10^{3} \mathrm{~s}^{-1}$. Deshpande and Fleck [2] researched the high strain rate compressive behaviours of two aluminium alloy foams, Alulight and Duocel were investigated using a split Hopkinson bar apparatus and direct impact tests. Over the range of nominal strain rates employed $\left(10^{-3}-5000 \mathrm{~s}^{-1}\right)$ no elevation of the dynamic stress versus strain curves is observed compared to the corresponding quasi-static curves. This result contrasts with the result reported by Cui et al. [3], who experienced an increase in quasi-static stress in Alulight foams for strain rates above $10^{3} \mathrm{~s}^{-1}$. It seems that the main cause of these discrepancies is the incompatibility of the definitions provided by various researchers of the basic foam parameters such as density, strain and smooth stress. Hall et al. [4] also compared the results of density change and strain rate on closed cell aluminum foams with a density of 0.34 $0.82 \mathrm{~g} / \mathrm{cm}$ in static compression experiments at strain rate, $1.5 \times 10^{-3} \mathrm{~s}^{-1}$ and dynamic experiments up to a maximum strain rate of $2 \times 10^{3} \mathrm{~s}^{-1}$ by Hopkinson bar. In both groups, the strong dependence of the collapse stress and the plateau stress on the foam density was clearly observed. The dynamic response of the foams to the strain rate change is similar to the results reported earlier, that is, the significant impact on $\sigma_{c r q s}$ and the indirect effect on $\sigma_{p l}{ }^{1}$ [4] is very similar to the findings of Dannemann et al. [5]. Dynamic response of panels consisting of two stainless steel AISI 304 panels and a middle layer of aluminum foam and fully clamped supports to a central impact of projectiles from aluminum foam with $50 \mathrm{~mm}$ long and $28 \mathrm{~mm}$ in diameter and speeds of $160-570 \mathrm{~m} / \mathrm{s}$ have been studied to compare the dynamic strength of sandwich panel and monolayer steel plates of equal weight and to investigate the effect of thickness of middle foam layer on panel strength [6-9]. From the experiments, numerical analyses, parametric studies, and transmitted pressure comparison study, the following conclusion can be drawn, with an increase in velocity, the compression ratio of all aluminum foams increased accordingly. The energy absorbed by the aluminum foam increased with the strain rate and velocity. Higher-density and thick aluminum foam had higher energy absorption capacity, but the thickness of the aluminum foam had a more significant effect than the density. The use of metal foam in the construction of sandwich panels, body of cars

$\mathbf{1}$ stress ahead of the shock wave(plateau stress) and modern aircraft and floating structures is very common [10]. Their low strength and high compressive strains, which usually occur at constant stresses, have made them attractive for impact energy absorption applications [11, 12]. Among them are the car bumper, the body of military vehicles, and the packaging of sensitive and breakable goods and equipment. Significant damping and acoustic properties are also widely used in the production of sound insulators and panels used in sound studios and amphitheaters. In this study, examples are made to investigate the behavior of static loading, after comparing the specimen behavior in static loading with aluminum foam, numerical simulation of the shock behavior of the specimen is also compared with the aluminum foam behavior $[13,14]$.

\section{Standard compression test specimen}

ISO 13314:2011 is used to the compression test of porous metals [15]. This standard offers square cross-section specimens with a length-to-width ratio of 1.5 to 2 or the same ratio of length to diameter for specimens with circular cross-sections. The compression speed is determined by the standard between $10^{-3} \mathrm{~s}^{-1}$ to $10^{-2} \mathrm{~s}^{-1}$. The way to make the specimen is that the pumice grains are poured into an iron mold, then aluminum is melted by the gas furnace and poured into the mold, the mold is shaken with a vibrator to allow the melt to penetrate between the grains well. The specimen should be centered at the top and bottom of the plates so that their line is aligned. The specimens were cast in cylinders with a diameter of $5 \mathrm{~cm}$ and a length of $8 \mathrm{~cm}$. In this study, two sizes of pumice almonds $(\max 3 \mathrm{~cm})$ and pea size $(\max 1$ $\mathrm{cm}$ ) are used. It uses two types of pumice with gray and cream colors. Since pumice particles do not have the same shape each step they fill into the mold, they give different percentages of volume and mass to the mold, but for pumice in a specified grading the volume occupied at each turn. When the pumice is poured into the mold is within an approximate range, for specimens made with almond size $45-50 \%$ of the volume of each specimen and pea size $52-58 \%$ of specimen volume. The top and bottom surfaces of the specimens must be perfectly flat and parallel to each other so that the axial force is transmitted completely to prevent buckling of the specimen. The specifications of the compression test specimens for this study are presented in Table 1.

The grain properties are obtained by compression test. The two grain sizes used are shown in Fig. 2. 
Table 1 Specifications of compression test specimens.

\begin{tabular}{lccc}
\hline $\begin{array}{l}\text { Test } \\
\text { number }\end{array}$ & $\begin{array}{c}\text { Specimen } \\
\text { weight }(\mathrm{g})\end{array}$ & Grading & $\begin{array}{c}\text { The volume percentage } \\
\text { of pumice }\end{array}$ \\
\hline 1 & 352 & pea-brown & 55 \\
2 & 353 & Pea-black & 55 \\
3 & 386 & almond-black & 45 \\
4 & 383 & almond-brown & 45 \\
\hline
\end{tabular}

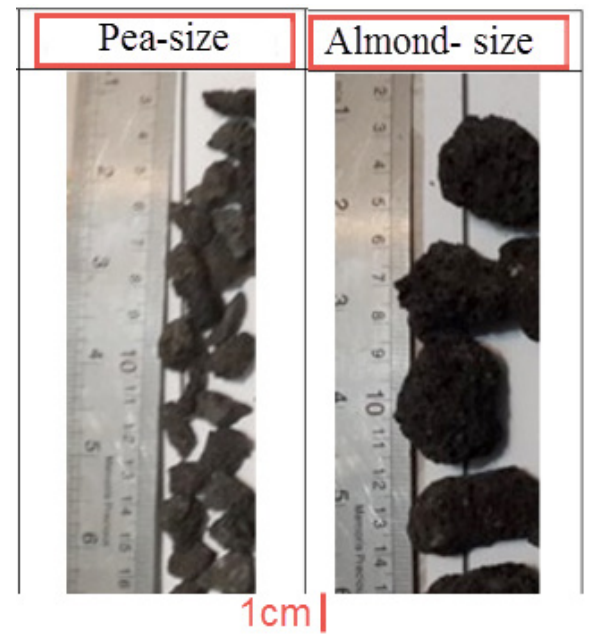

Fig. 2 The pumice size used in the study.

The pumice grains are poured into the matrix and compressed using the punch as seen in Fig. 3.

In this study, a press machine with a compression rate of $2 \mathrm{~mm} / \mathrm{min}$ was used to obtain the graph of the properties of the pumice grains. The strain-stress diagram of the two types of pumice grain used in the research is shown in Fig. 4.

Fig. 5 shows how to make compression test specimens.

The test specimens made are shown in Fig. 6.

In this study, a press machine with a maximum capacity of 30 tons is used, which is shown in Fig. 7.

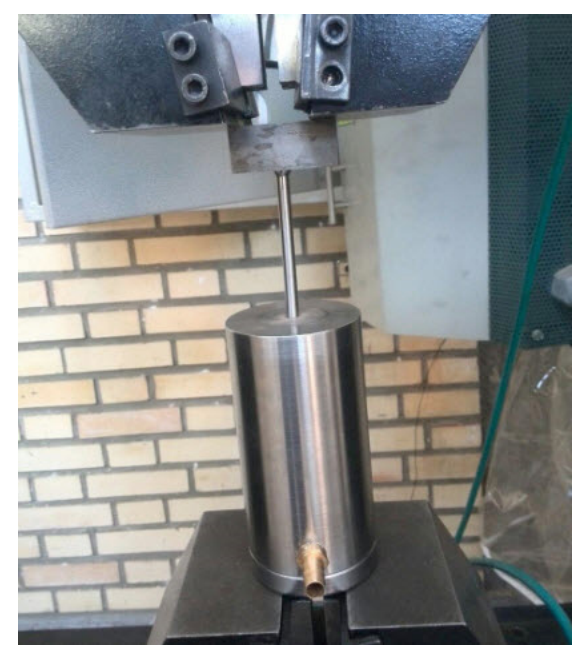

Fig. 3 Compression test on the pumice grain.

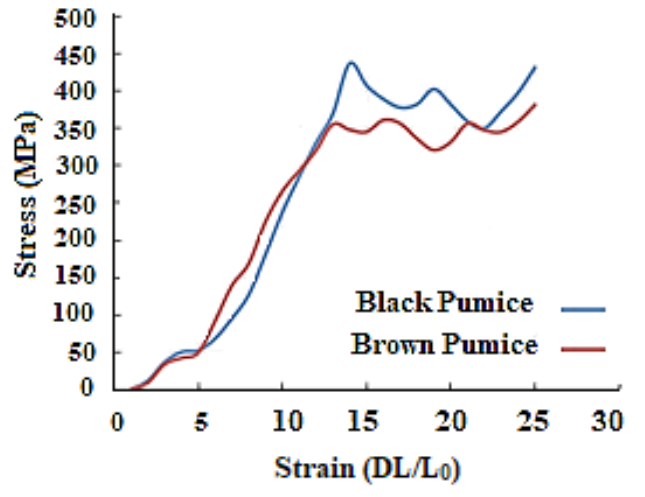

Fig. 4 Strain-stress diagram for two different pumice grain.

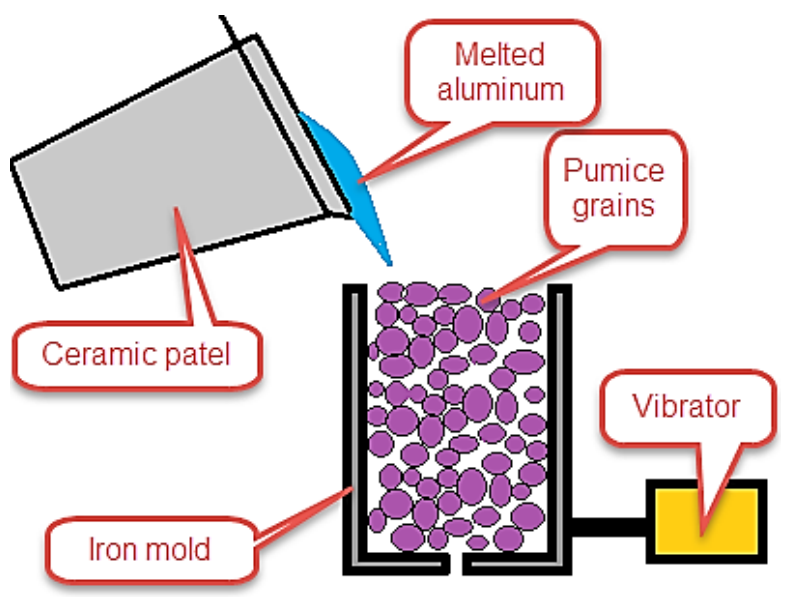

Fig. 5 Made pressure test specimens.
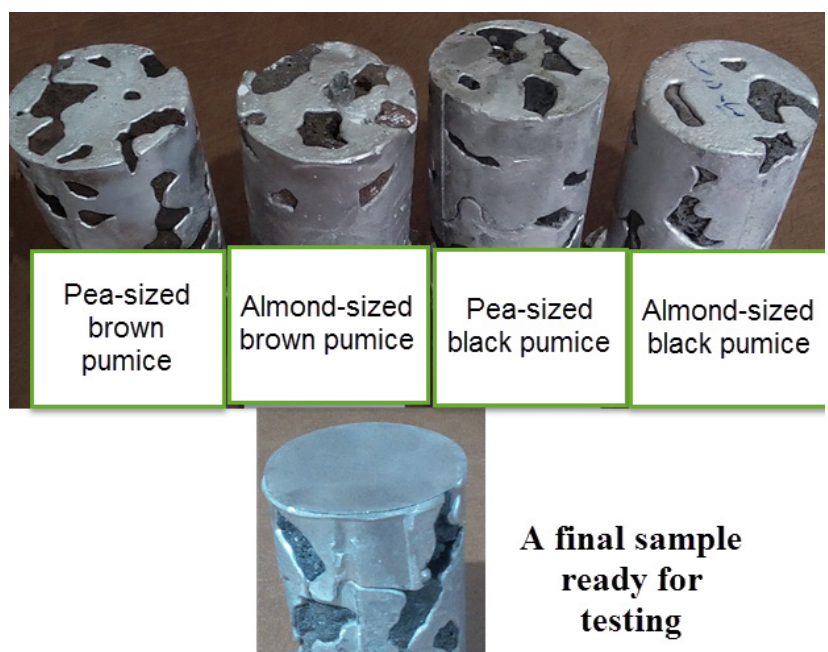

Fig. 6 Compression test specimens.

The pressure test provides the force-displacement diagram of the specimens, which can be used to represent the stress-strain engineering diagram of the specimen in Figs. 8 to 11. 


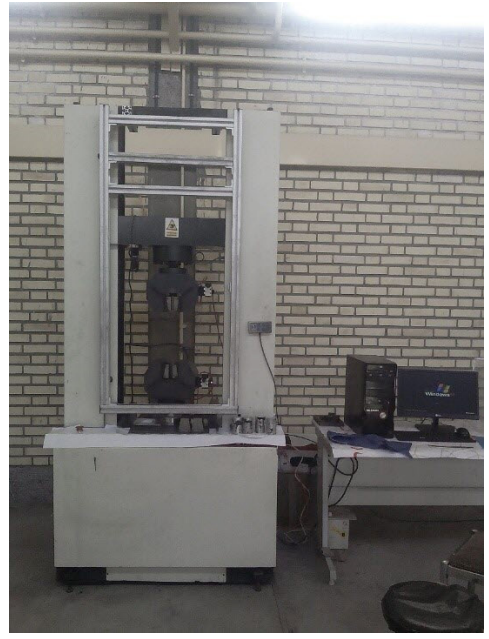

Fig. 7 Compression testing machine.

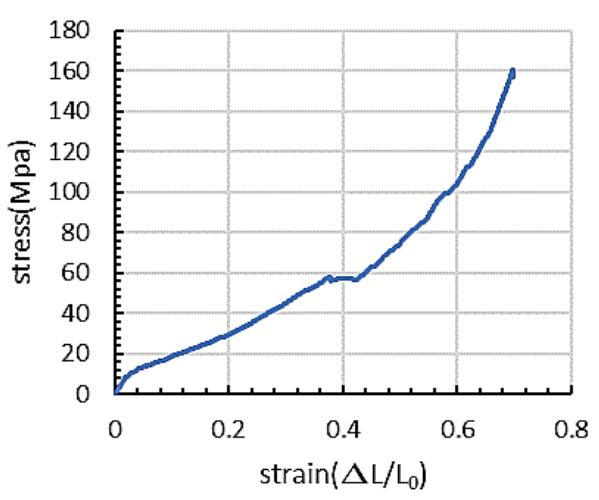

Fig. 8 Stress-strain diagram of specimen 1.

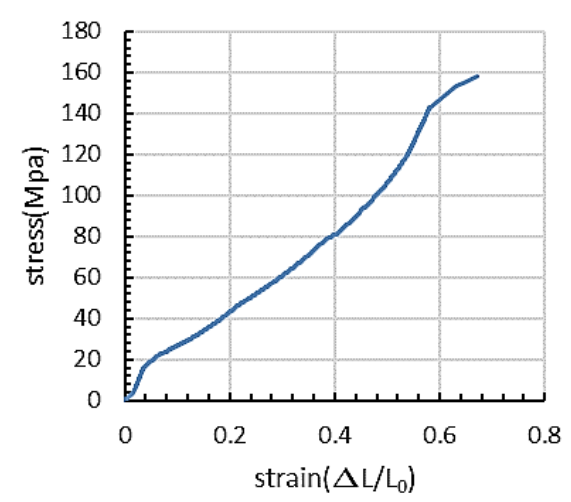

Fig. 9 Stress-strain diagram of specimen 2.

\section{Analysis of quasi-static loading results}

According to the images of the pressure test specimens of this study in Fig. 12 and the aluminum foam pressure test specimens in Fig. 13, the deformation patterns of the specimens are similar to those of aluminum foam under pressure test.

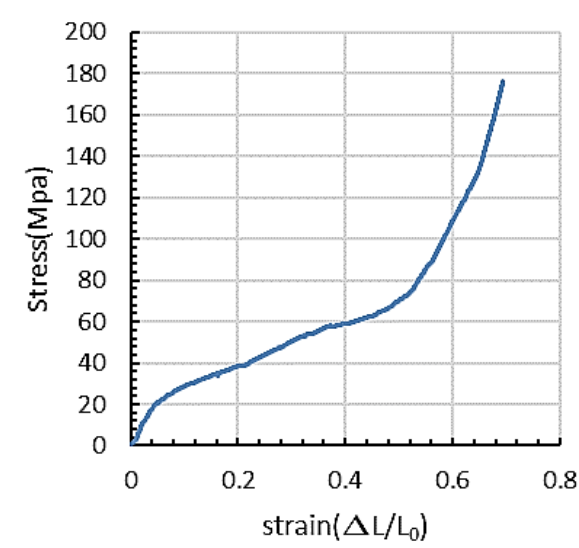

Fig. 10 Stress-strain diagram of specimen 3.

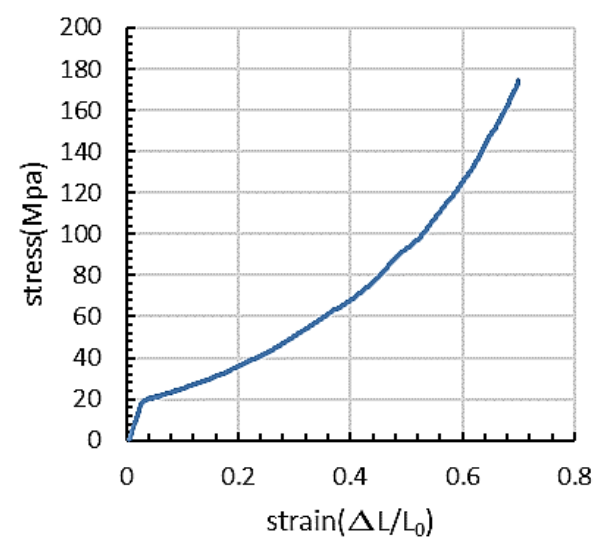

Fig. 11 Stress-strain diagram of specimen 4.

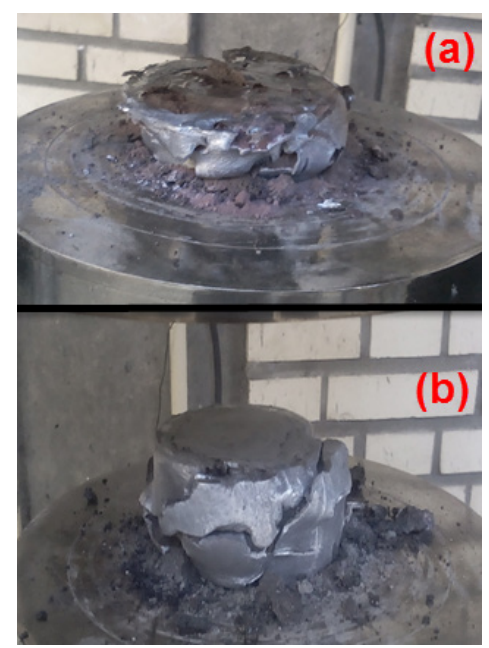

Fig. 12 Two cases of samples after testing (a) specimen 1; (b) specimen 2.

The engineering strain diagram of this material, which you can see in an example in Fig. 14, is similar to the aluminum foam containing three main steps. Initially, the elastic bending of the cell wall gives rise to an elastic region in the 


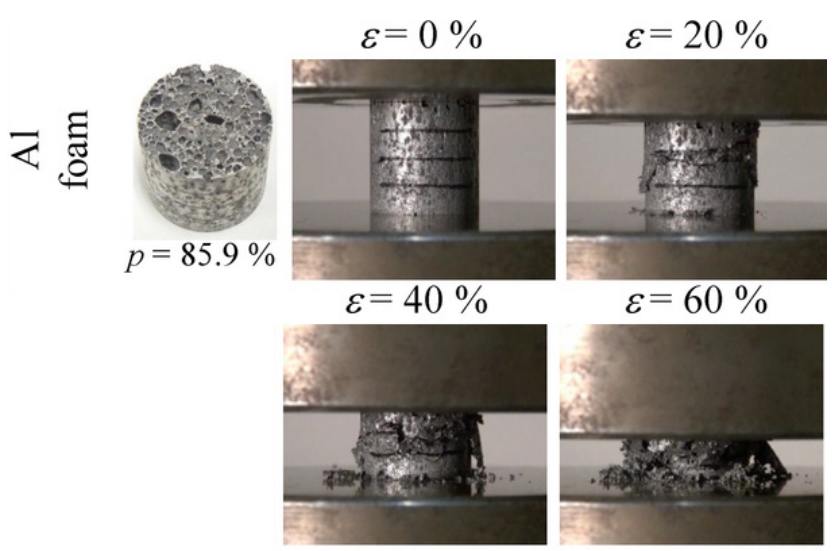

Fig. 13 Aluminum foam compression test specimens [1].

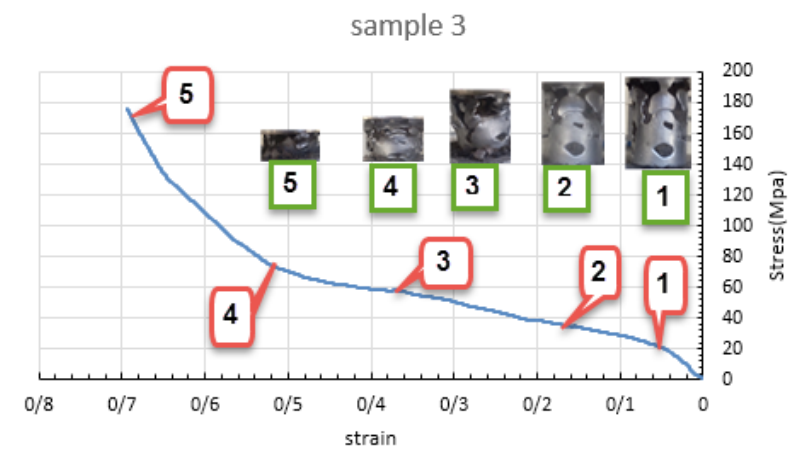

Fig. 14 Stages of compression specimen 3.

stress-strain curve of material engineering (up to point 1 in Fig. 14). Then, like the foam, the buckling and plastic collapse of the cells forms a large and relatively smooth region along the primary elastic region (points 1 to 4 ).

From point 4 onwards, as most of the particles of the foam condensation shell collide and the density of the material becomes closer to the density of aluminum.

\section{Numerical simulation}

Given the similarity of the strain-strain diagram of the specimens in this study to the aluminum foam, it is predicted to have a similar behavior to the aluminum foam when exposed to the blast wave, therefore, it can be predicted that the models used for foam shock loading can also be used for this material. Thus, Table 2 material models, commonly used to define metal foams in Autodyn, are used to simulate the new material structure.

Table 2 Models used for modeling materials in simulation.

\begin{tabular}{lcc}
\hline Strength model & Equation of state (EOS) & Material \\
\hline Crushable Foam & Linear & Aluminum with \\
& pumice particles \\
- & Ideal gas & Air \\
- & JWL & C4 \\
\hline
\end{tabular}

The specimens are attached to the shock tube with a number of screws, assuming that the edges of the specimen are clamped. The explosive charge is located on the other side of the shock tube and the detachable wire exits. The specimens were also made as a sandwich panel, with an aluminum foam replacement material in core and aluminum 3105 shells. The simulation geometry is visible in Fig. 15.

The simulation of the problem in the Autodyn software shown in the Fig. 16. Because of the geometry and the loading of the problem have axial symmetry, there is no need to model the specimen in three-dimensional form and only part of the problem is modeled in two-dimensional form. To measure parameters such as the speed and pressure of the blast wave in air Eulerian gauges and Lagrangian gauges were used to measure the deformation of the specimen.

In software for air as a filler, conditions such as internal energy and density must be defined. Table 3 shown these parameters for air as Eulerian filler.

Definition of boundary conditions is necessary for each problem, in the simulation of this study, for backbone conditions and for assuming infinite space around the

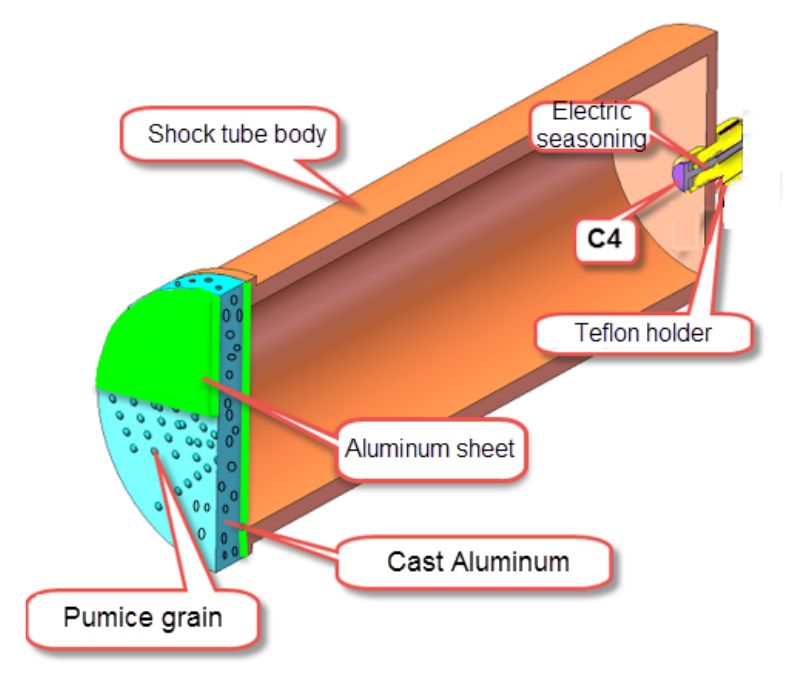

Fig. 15 Simulation geometry.

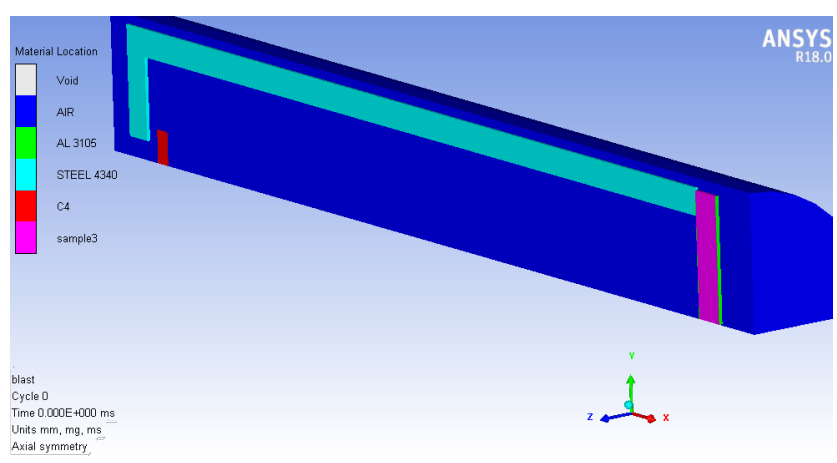

Fig. 16 Modeled two-dimensional geometry of the problem in Ansys-Autodyn. 
Table 3 Initial conditions defined for air as Eulerian filler.

\begin{tabular}{lc}
\hline Name & Initial \\
\hline Material & Air \\
Density & $1.23 \mathrm{E}-03$ \\
Internal Energy & $2.08 \mathrm{E}+5$ \\
Shell Thickness & $0.00 \mathrm{E}+00$ \\
X Velocity & $0.00 \mathrm{E}+00$ \\
Y Velocity & $0.00 \mathrm{E}+00$ \\
\hline
\end{tabular}

boundary condition that prevents wave reflection after collision with the problem modeling boundaries that both you can see these boundary conditions in Table 4.

\section{Results and discussion}

In order to check the validity of the simulation results in Section 5, the problem modeled by the crush able foam method is evaluated by Radford et al. [6]. The geometry used in the evaluation is shown in the problem under investigation is shown in Fig. 17. The target plate is sandwiched with aluminum foam core and AISI304 steel shell with three different thicknesses, which has clamped supports. The projectile is also a cylindrical of aluminum foil Aloporas (a type of closed cell aluminum foam) that hits the target at speeds of 160 to $570 \mathrm{~m} / \mathrm{s}$ and measures the deformation of the specimens.

Approximate density of foam core used at about $\rho_{c}=430 \mathrm{~kg} / \mathrm{m}^{3}$ in this paper, two thicknesses of 10 and $22 \mathrm{~mm}$ were used for testing, the thickness of which was 1.18 and $0.88 \mathrm{~mm}$, respectively. Projectile with approximate length $L_{0}=50 \mathrm{~mm}$ and the diameter $d=28.6 \mathrm{~mm}$ Aloporas foam with approximate density between $380-490 \mathrm{~kg} / \mathrm{m}^{3}$ the projectile is fired by a gas gun at $4.5 \mathrm{~m}$ in length and is between 160 and $570 \mathrm{~m} / \mathrm{s}$. Table 5 compares the results of the simulation in Autodyn with the reference [6].

According to the Table 5, it is observed that the results of empirical paper testing and simulation for foam in Autodyn are about 10 to $20 \%$ different, which can be due to various factors such as inability of software in complete modeling of the material and receiving properties are

Table 4 Model boundary conditions.

\begin{tabular}{lc}
\hline Type & Flow out (Euler) \\
\hline Coordinate System & 0 \\
Preferred Material & All Equal \\
Type & General 2D Velocity \\
Coordinate System & 0 \\
Constant X-Velocity & $0.00000 \mathrm{E}+00$ \\
Constant Y-Velocity & $0.00000 \mathrm{E}+00$ \\
\hline
\end{tabular}

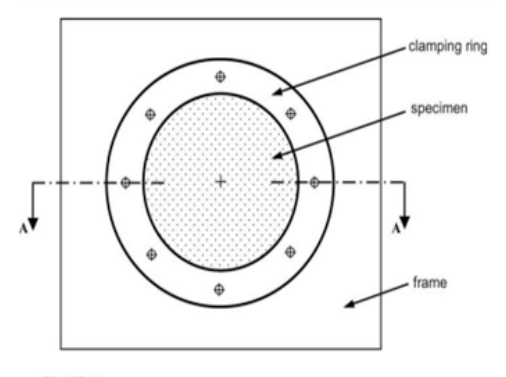

(a)

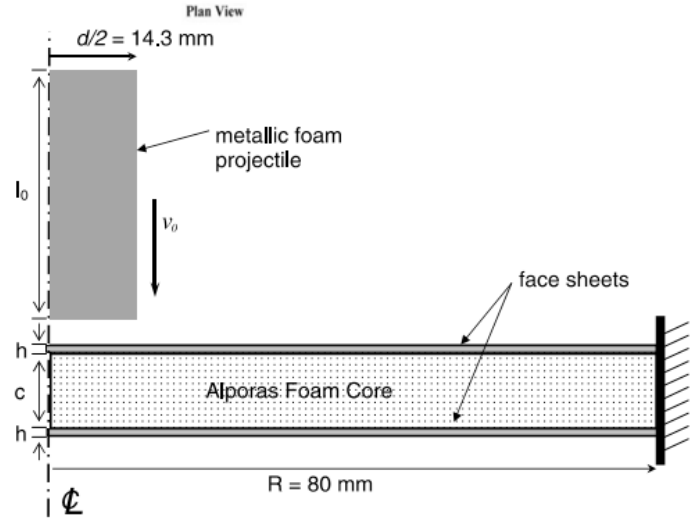

Fig. 17 Evaluation geometry (a) top view of the target; (b) target and projectile side view [6].

Table 5 Comparison of experimental results [6] with simulation results with crushable foam method.

\begin{tabular}{lcccccc}
\hline $\begin{array}{l}C \\
(\mathrm{~mm})\end{array}$ & $\begin{array}{c}\rho_{P} \\
\left(\mathrm{kNm}^{-2}\right)\end{array}$ & $\begin{array}{c}l_{0} \\
(\mathrm{~mm})\end{array}$ & $\begin{array}{c}v_{0} \\
\left(\mathrm{~ms}^{-1}\right)\end{array}$ & $\begin{array}{c}\text { In the } \\
\text { Article } \\
(\mathrm{mm})\end{array}$ & $\begin{array}{c}\text { Research } \\
\text { study } \\
(\mathrm{mm})\end{array}$ & $\begin{array}{c}\% \\
\text { error }\end{array}$ \\
\hline 10 & 433 & 47 & 160 & $2 / 0$ & $2 / 4$ & $20 \%$ \\
10 & 388 & 50 & 321 & $4 / 4$ & $5 / 1$ & $15 \%$ \\
10 & 509 & 45 & 434 & $8 / 1$ & $9 / 4$ & $16 \%$ \\
10 & 503 & 48 & 551 & $12 / 8$ & 14 & $9 / 3 \%$ \\
22 & 393 & 51 & 157 & $1 / 1$ & $1 / 3$ & $18 \%$ \\
22 & 487 & 48 & 265 & $3 / 1$ & $3 / 7$ & $19 \%$ \\
22 & 490 & 47 & 414 & $5 / 7$ & $6 / 7$ & $17 \%$ \\
22 & 470 & 48 & 570 & $9 / 2$ & 11 & $19 \%$ \\
\hline
\end{tabular}

incomplete and ideal software conditions for the supports. an example of the simulation and impact model of the projectile in the Autodyn software shown in Fig. 18.

In Section 5, the parameter is compared with the paper [6] and the center displacement of the specimens is reported, in the Fig. 19, displacement of the center of the first sample of the evaluation simulation is observed.

After evaluating the Crushable Foam model in the metallic foam simulation, the following new material structure under shock loading is examined by simulation Response Surface Methodology was used to design the experiment. Surface Response Methodology is a set of statistical techniques and applied mathematics for building 


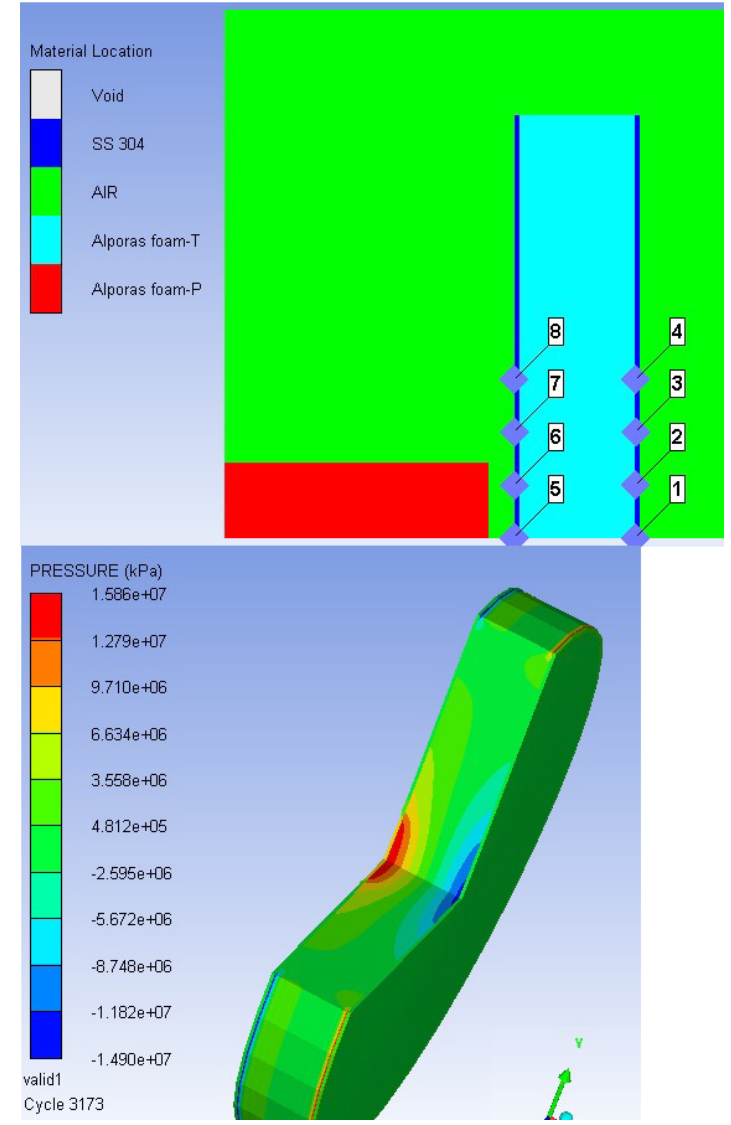

Fig. 18 (a) Pressure contour after projectile collision and (b) two-dimensional simulation with axial symmetry geometry in Autodyn

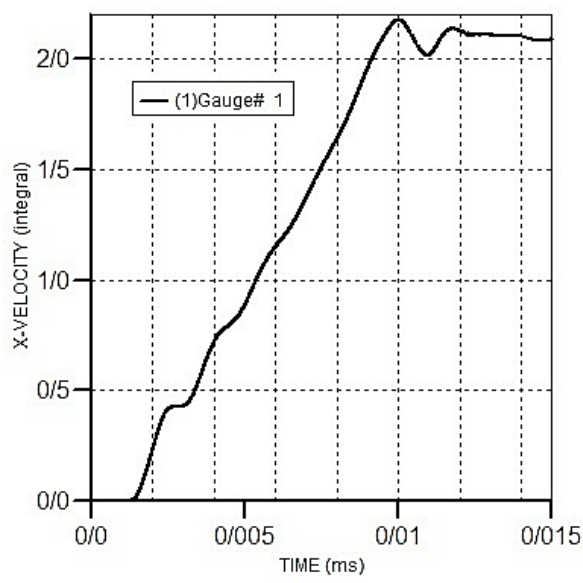

Fig. 19 Center displacement diagrams of the first specimen of evaluation.

experimental models. The goal in response procedure designs is to optimize the response, the output variable, which includes several independent variables and input variables. The levels of numerical variables and the proposed experiments are shown in Tables 6 and 7.

Two of the results of the experiments are shown in Figs. 20 and 21.

(a)

\begin{tabular}{lcccc} 
Table 6 Levels intended for numerical factor. \\
\hline & A & B & C & D \\
\hline Thickness of the specimens (mm) & 20 & $28 / 5$ & $36 / 5$ & 45 \\
Explosive forming C4 (gr) & 10 & $11 / 5$ & $13 / 5$ & 15 \\
\hline
\end{tabular}

Table 7 Suggested experiments Response Surface Method (RSM).

\begin{tabular}{lcccc}
\hline $\begin{array}{l}\text { Test } \\
\text { number }\end{array}$ & $\begin{array}{c}\text { The type } \\
\text { of pumice }\end{array}$ & $\begin{array}{c}\text { Pumice } \\
\text { sizes }\end{array}$ & $\begin{array}{c}\text { Explosive } \\
\text { forming C4 } \\
(\mathrm{gr})\end{array}$ & $\begin{array}{c}\text { Specimen } \\
\text { Thickness } \\
(\mathrm{mm})\end{array}$ \\
\hline 1 & Brown & Peas & 10 & $28 / 5$ \\
2 & Black & Almond & 15 & 20 \\
4 & Brown & Peas & 15 & 45 \\
4 & Black & Almond & 15 & 45 \\
5 & Black & Almond & 10 & $28 / 5$ \\
6 & Black & Almond & 10 & $28 / 5$ \\
7 & Brown & Almond & 10 & 45 \\
8 & Brown & Peas & 15 & 20 \\
9 & Black & Peas & $11 / 5$ & 45 \\
10 & Black & Peas & $13 / 5$ & 20 \\
11 & Black & Peas & $11 / 5$ & $28 / 5$ \\
12 & Brown & Almond & 15 & $36 / 5$ \\
13 & Brown & Almond & 10 & 20 \\
\hline
\end{tabular}

Comparison of energy absorption diagram of this material with aluminum foam under shock loading shown in Fig. 22 and Fig. 23.

As can be seen from the image above, the energy absorption of the specimen, such as aluminum foam, is very high, indicating that it can be used as an energy absorber and bumper. By entering the response from the simulation into the Design Expert software and specifying a linear model, it proposes the following models for the response (displacement of the specimen center) within the specified range for the parameters. The linear models provided by the software are listed in Table 8 .

\section{Conclusion}

According to the results of the quasi-static loading the behavior of the material is very similar to that of aluminum foam and has a wide plastic area which indicates high material absorption ability like aluminum foam. The diagram of this material, like aluminum foam, has three main elastic components, the collapse of cells and their plastic deformation, which ends with the crushing of the pumice particles and ultimately the condensation phase and comparison of the results of different specimens shows that the specimens with higher porosity have better energy absorption. In this study, the approximation of the properties of the specimens for static and impact loading with aluminum foam was found to be similar, and therefore this material can be used in some 

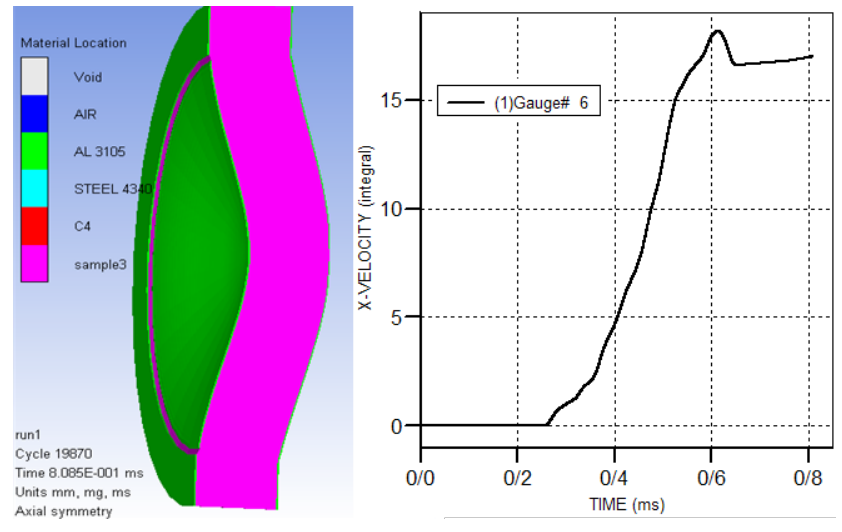

Fig. 20 Displacement the specimen center for the first simulation experiment.
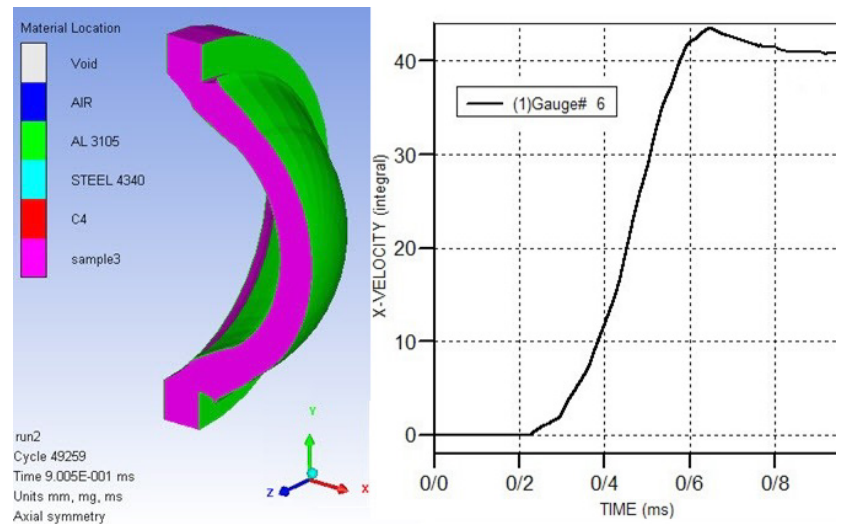

Fig. 21 Displacement the specimen center for the second simulation experiment.

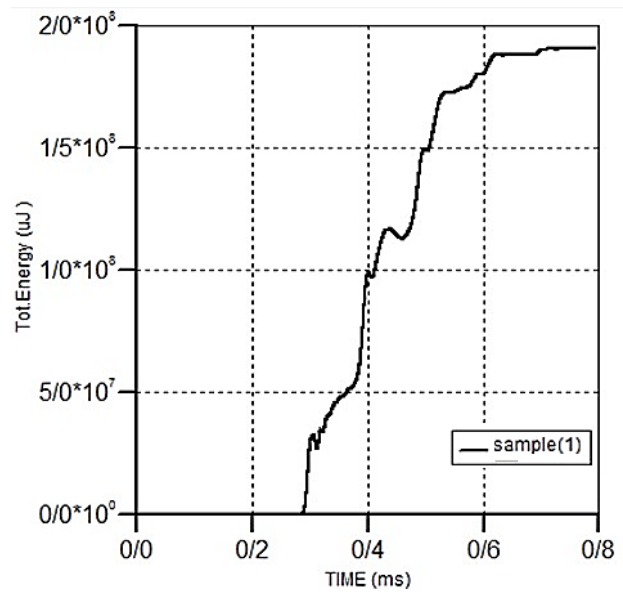

Fig. 22 Energy diagram for first specimen (specimen including sheet and core).

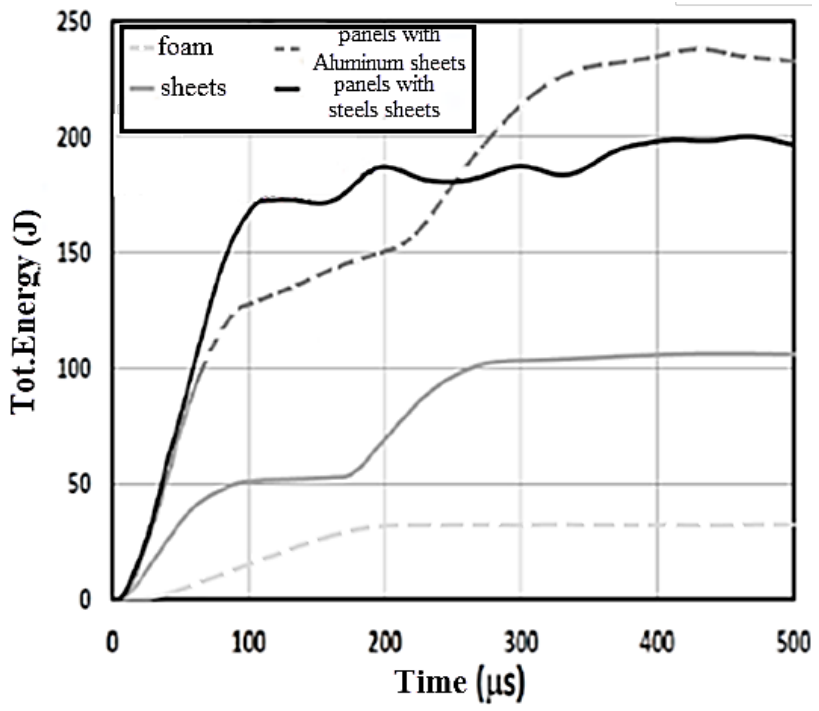

Fig. 23 Energy diagram of specimens from source [16].

Table 8 Linear models provided by software.

\begin{tabular}{lc}
\hline Specimen of Brown Almond & Specimen of Brown Peas \\
\hline $\operatorname{Ln}(R 1)=+1.44009$ & $\operatorname{Ln}(R 1)=+1.59223$ \\
$-0.041690 *$ with & $-0.041690 *$ with \\
$+0.25192 * \mathrm{C}_{4}$ mass & $+0.25192 * \mathrm{C}_{4}$ mass \\
\hline Specimen of Black Almond & Specimen of Black Peas \\
$\operatorname{Ln}(R 1)=+1.46841$ & $\operatorname{Ln}(R 1)=+1.62054$ \\
$-0.041690 *$ with & $-0.041690 *$ with \\
$+0.25192 * \mathrm{C}_{4}$ mass & $+0.25192 * \mathrm{C}_{4}$ mass \\
\hline
\end{tabular}

applications of aluminum foam, which usually have no economic justification. The two types of pumices used in this study the static loads that scientifically and the explosive loads, which have empirically very close results from the parameters investigated and relationships are obtained and presented by the Design Expert. Determine the objective function that is the displacement of the specimen center within the specified range for the parameters and the result of the comparison of numerical simulations and experimental tests shows relatively good agreement between them.

\section{Acknowledgement}

We would like to thank the Bu-Ali Sina University Laboratory for conducting a research test. 


\section{References}

[1] Kenny, L. D. "Mechanical Properties of Particle Stabilized Aluminum Foam", Materials Science Forum, 217-222, pp. 1883-1890, 1996.

https://doi.org/10.4028/www.scientific.net/MSF.217-222.1883

[2] Deshpande, V. S., Fleck, N. A. "High strain rate compressive behavior of aluminum alloy foams", International Journal of Impact Engineering, 24(3), pp. 277-298, 2000. https://doi.org/10.1016/S0734-743X(99)00153-0

[3] Cui, L., Kiernan, S., Gilchrist, M. D. "Designing the energy absorption capacity of functionally graded foam materials", Materials Science and Engineering: A, 507(1-2), pp. 215-225, 2009. https://doi.org/10.1016/j.msea.2008.12.011

[4] Hall, I. W., Guden, M., Yu, C. J. "Crushing of aluminum foams: density and strain rate effects", Scripta Materialia, 43(6), pp. 515-521, 2000.

https://doi.org/10.1016/S1359-6462(00)00460-7

[5] Dannemann, K. A., Lankford, J., Nicholls, A. E. "The Mechanism of Strain Rate Strengthing during Dynamic Compression of Closed-Cell Aluminum Foam", AIP Conference Proceedings, 620(1), pp. 729-734, 2002.

https://doi.org/10.1063/1.1483641

[6] Radford, D. D., McShane, G. J., Deshpande, V. S., Fleck, N. A. "The response of clamped sandwich plates with metallic foam core to simulated blast loading", International Journal of Solids and Structures, 43(7-8), pp. 2243-2259, 2006. https://doi.org/10.1016/j.ijsolstr.2005.07.006

[7] Raj, R. E., Daniel, B. S. S. "Aluminum Melt Foam Processing for Light-Weight Structures", Materials and Manufacturing Processes, 22(4), pp. 525-530, 2007. https://doi.org/10.1080/10426910701236072

[8] Fiedler, T., Ochsner, A., Gracio, J., Kuhn, G. "Structural Modeling of the Mechanical Behavior of Periodic Cellular Solids: Open-Cell Structures", Mechanics of Composite Materials, 41(3), pp. 277-290, 2005. https://doi.org/10.1007/s11029-005-0054-4

[9] Evans, A. G., Hutchinson, J. W., Ashby, M. F. "Multifunctionality of cellular metal systems", Progress in Materials Science, 43(3), pp. 171-221, 1998.

https://doi.org/10.1016/S0079-6425(98)00004-8
[10] Nemat-Nasser, S., Kang, W. J., McGee, J. D., Guo, W. G., Issac, J. B. "Experimental investigation of energy-absorption characteristics of components of sandwich structures", International Journal of Impact Engineering, 34(6), pp. 1119-1146, 2007. https://doi.org/10.1016/j.ijimpeng.2006.05.007

[11] Stephani, G., Andersen, O., Göhler, H., Kostmann, C., Kümmel, K., Quadbeck, P., Reinfried, M., Studnitzky, T., Waag, U. "Iron Based Cellular Structures - Status and Prospects", Advanced Engineering Materials, 8(9), pp. 847-852, 2006. https://doi.org/10.1002/adem.200600078

[12] Wang, P., Xu, S., Li, Z., Yang, J., Zhang, C., Zheng, H., Hu, S. "Experimental investigation on the strain-rate effect and inertia effect of closed-cell aluminum foam subjected to dynamic loading", Materials Science and Engineering: A, 620, pp. 253-261, 2015. https://doi.org/10.1016/j.msea.2014.10.026

[13] Hanssen, A. G., Enstock, L., Langseth, M. "Close-range blast loading of aluminum foam panels", International Journal of Impact Engineering, 27(6), pp. 593-618, 2002. https://doi.org/10.1016/S0734-743X(01)00155-5

[14] Lopatnikov, S. L., Gama, B. A., Haque, J., Krauthauser, C., Gillespie, J. W., Gudan, M., Hall, I. W. "Dynamics of metal foam deformation during Taylor cylinder-Hopkinson bar impact experiment", Composite Structures, 61(1-2), pp. 61-71, 2003. https://doi.org/10.1016/S0263-8223(03)00039-4

[15] International Organization for Standardization "ISO 13314:2011 Mechanical testing of metals - Ductility testing - Compression test for porous and cellular metals", International Organization for Standardization, Geneva, Switzerland, 2011.

[16] Ghalami-Choobar, M., Sadighi, M. "Investigation of high velocity impact of cylindrical projectile on sandwich panels with fibermetal laminates skins and polyurethane core", Aerospace Science and Technology, 32(1), pp. 142-152, 2014.

https://doi.org/10.1016/j.ast.2013.12.005 